\title{
Historical Reflection on Learning Theories and Instructional Design
}

\author{
Robert D. Tennyson \\ University of Minnesota, United States
}

\begin{abstract}
Employing my research and practical experience in the field of educational psychology, with a specialty in instructional design and technology, I would like to reflect on the theoretical foundations of instructional design. My purpose is to show the growth of the field through theories associated with learning psychology and educational technology. Both human psychology and technology are the main foundations for instructional psychology. Evaluation and assessment continue to be integral to the field but more in the form of tools. Included is my view of the field in reference to work I and my colleagues have done in what we label as a linking theory of instructional design. That is, linking learning theory directly with research findings and practice I argue that educators need to clearly propose and define their own theoretical foundations when engaging in the design of effective learning environments.
\end{abstract}

Keywords: Instructional technology; Learning theory; Instructional design; Technology; Theoretical foundations

\section{Background}

The roots of instructional theory can be traced to early efforts by educational psychologists to develop a connection between the science of psychology and the practical application of learning theory in educational settings. Two theorists of particular importance at the turn of the century were John Dewey (1910), who envisioned a special linking science between learning theory and educational practice, and Edward Thorndike (1913), who investigated principles of learning that could be directly applied to the teaching process (i.e., the laws of effect and exercise). Thorndike developed a body of instructional design principles that included task analysis and teaching methods based on his research findings and student evaluation methods.

Contemporary foundations of instructional theory may be rooted both in behaviorism and in the general trend of the 1950s toward applying scientific approaches to the social sciences. Attempts to integrate psychology and instructional technology had emerged during and after World War II as educational psychologists became involved with the U.S. military in efforts to research and develop military training materials and instruction. The focus of instructional research programs was twofold: first, development of ISD (instructional systems design) methodologies for the analysis of content and tasks; and, second, testing of variables of design to achieve specific learning outcomes. At that time, the ISD approach to learning was related to theories of automation and the concept of systems as a complex interrelationship of components, flow and 
control of information, thorough analysis of a task, and careful planning and decision-making. Intrinsic to such instructional theories was the embrace of advanced technology and the "automation" of the learning process (Finn, 1957).

\section{Technology and Instruction}

Research testing the programmed instruction paradigm (e.g., step-by-step versus branching) and the development of teaching machines pioneered by Skinner are of particular interest to the historical development of instructional theory. A pivotal article by Skinner (1954) entitled, The Science of Learning and the Art of Teaching, outlines principles of a technology of instruction which include small, incremental steps, sequencing simple to complex, learner participation, reinforcement of correct responses, and individual pacing. While Skinner's contributions are only of material focus in this section, it is significant that several of the leading figures in the early development of instructional theory (e.g., Robert Gagné, Leslie Briggs, and Robert Glaser) were also proponents of programmed instruction and later in varying degrees moved away from the behavioral paradigm to cognitive theory.

In the 1950s, two developments outside the fields of education and psychology played an important role in establishing momentum for increased instructional theory research. First, the post World War II baby boom presented a challenge to the existing educational system. Within a very short period in the early 1950s, schools were forced to absorb a significant increase in students, necessitating rapid changes in instructional methods. Second, in 1957, the Russians launched Sputnik, shattering the comfortable image of American educational and technological superiority and calling into question the adequacy of contemporary methods of instruction. In response to the perceived challenge, the United States government increased its interest in and funding of research and development of new curricular and teaching methods.

\section{Early Developments}

In the early stages, instructional theory was defined primarily in behaviorist terms as follows:

Small, incremental steps sequenced to link information in a logical order; active learner participation in responding to instructional stimuli with immediate feedback as a positive reinforcer. Learner progress is based on successful attainment of defined behavioral objectives.

The instructional design field was seen as an attempt to develop a single, ideal instructional theory based in systems theory that would specify teacher characteristics, classification and evaluation procedures, and means to modify the design systems being tested. The goal from this perspective was the development of instructional programs that would enable the majority of students to achieve levels of performance that were pre-determined in terms of behaviorally defined objectives. Robert Mager's (1962) influential book, Preparing Instructional Objectives, helped to 
popularize the use of measurable behavioral objectives. Much of the early work in the ID (instructional development) field was directed at the establishment of taxonomies for classifying learning objectives and codifying the interactions between the various classifications.

\section{Behavioral Influences}

Throughout most of the 1960s, instructional research continued to be based on behaviorist learning models and theories. Empirical studies sought to determine the most effective means of implementing a stimulus-response-reinforcement model (i.e., operant model) to insure that the prescribed learning outcomes would be achieved. A major goal of instructional research centered on methods of task analysis and the development of behavioral objectives for learning. The goals of the behavioral task analysis were on (a) identifying small, incremental tasks or subskills which the learner needed to acquire for successful completion of the instruction; (b) preparing specific behavioral objectives which would lead to the acquisition of those subskills; and (c) sequencing subskill acquisition in the order which would most efficiently lead to successful learner outcomes. Also important to researchers' investigations was the search for variables of individual differences in what the learner brings to the learning task. The concept of individual differences in the behavioral paradigm was on how to manipulate the environment to account for student differences. For example, students with a high aptitude in a given content would receive an instructional strategy that would be different for students with a low aptitude. This particular strategy was labeled aptitude treatment interaction (ATI).

As I have noted, programmed instruction had been a key element in the design of instruction in the 1960s. Toward the end of that decade, however, the interest in such instruction declined. Research findings revealed that the programmed materials were often no more effective than conventional materials and students often found the materials to be uninteresting. In addition, many of the principles of learning proposed by Skinner and other behaviorists were found to be untrue, especially for the complex learning tasks required in the classroom. Research in the early 1970s revealed findings that contradicted previous ideas about the role those behavioral principles such as feedback, rewards, sequencing, and definition of objectives played in the learning process.

\section{Contributors to Instructional Theory}

A major contributor to instructional theory development in the 1960s was Robert Gagné, who theorized that the acquisition of knowledge is facilitated by the hierarchical sequencing of content from elemental subordinate information to more complex skills (Gagné, 1962). Additional contributors, but in contrast to the behavioral paradigm, were psychologists who proposed cognitive-based paradigms. For example, David Ausubel's theory of progressive differentiation proposed the use of advance organizers (broad, general ideas) followed by a sequence of more concrete and detailed ones (Ausubel, 1969). Jerome Bruner proposed that ideas should be reintroduced in increasingly complex ways as the learner matures (Bruner, 1964). Other significant instructional theory contributions during this period were made by Susan Markle and J. William Moore for their development of instructional design theories to improve concept acquisition. 


\section{Transition to Cognitive Learning Theory}

In the late 1960s and throughout the 1970s, the behavioral paradigm gradually gave way to the cognitive approach to learning. Beginning with Bruner (1964), instructional researchers began to move away from the stimulus-response-reinforcement model of instruction and to develop instructional theories based, at least in part, on the mental processes of the learner. The definition of instructional design at this point shifted to considerations of learning theory and to the development of models linking those theories to the design of instruction. The result was rapid proliferation of instructional systems design models and instructional design theories covering a wide range of perspectives as psychologists and educators pursued their individual ideas in a generally competitive environment.

Instructional design researchers in the 1970s tried to establish a more complete picture of the conditions of learning. Theories sought to incorporate individual differences into the instructional design process, leading to the extensive use of pretests and formative evaluation procedures. Sequencing still played a vital role, but its direction was somewhat altered as instructional theorists sought to develop sequences that corresponded most closely with the learner's individual cognitive growth (Snow, 1997). Research was centered on identifying those aspects of cognitive psychology that were central to the design of instruction. An example of this trend was the work of Joseph Scandura that led directly to his theory of structured learning. Scandura (1970) focused his theory in large part on rule acquisition and structure of the knowledge base. Shifting in the late 1980s to ISD methodology, Scandura continues to contribute to the instructional design field by developing automated systems of instructional design (Scandura, 2001).

\section{Information Analysis}

Throughout the 1970s, information analysis procedures (including task and content) shifted away from behavioral objectives toward an understanding of stages of competent performance in various domains of knowledge and skills relevant to education. Cognitive researchers used information analysis to identify the levels of learning that distinguish a novice from an expert in a subject-matter domain. Much of the research work was on describing the complex structure and sequencing of cognitive processes such as attention, memory, and recognized the importance of perception in the performance of individuals who are highly skilled in specific domains.

Content/Task analyses. This trend toward methods of information analysis continued with advancements coming first from cognitive psychology and more recently from constructivist theory. Thus, an important component of instructional design theory is the analysis of the information-to-be-learned. Two basic types of information analyses included: (a) a content analysis, which focuses on defining the critical attributes of the given subject matter and the relationship of those attributes according to superordinate and subordinate organizations; and, (b) a task analysis, which focuses on a hierarchical organization of human performances. Both of these analyses identify the external structure of the information but do so independent of how it might actually be stored in human memory. Research in cognitive psychology on human memory 
suggests that the internal organization of information in a knowledge base is formed more on employment needs rather than by attribute or hierarchical associations (Carroll, 1993). That is, the utility of the knowledge base is attributed to its situational organization, not the amount of information. The implication of a knowledge base organization is the need for a further analysis of the information to better understand the possible internal organization and representation of the knowledge.

Merrill (1997) states that a ". . content analysis focuses on components, not integrated wholes . . ." in describing the limitations of what Merrill terms First Generation Instructional Design (ID $)_{1}$. The components that result from a content analysis are individual items, such as facts, concepts, principles and procedures. Instruction derived from this form of content analysis may allow students to pass tests, but is not effective in helping students integrate information into meaningful wholes. These integrated wholes are essential for understanding complex and dynamic phenomena and for using knowledge in complex problem solving situations. That is, a welldeveloped cognitive structure (schema) is necessary for new information to be learned meaningfully and for accurate recall later. Merrill suggests that this cognitive structure consist of mental models, but that no $\mathrm{ID}_{1}$ content analysis procedure takes this notion of mental models (cognitive structure) into account. Most of these task and content analysis procedures were developed before interactive media that were widely available and resulted in passive, rather than interactive, instruction. It follows that these task and content analysis procedures are not well suited to highly interactive instructional situations, such as computer based simulations (Breuer \& Kummer, 1990).

Problem solving analysis. Better organization in memory may also imply better accessibility within the knowledge base for such higher order cognitive activities as problem solving and creativity. To understand the nature of the knowledge base organization, cognitive psychologists analyze problem complexity and the way individuals try to solve given problems. By analyzing problems, it is possible to identify the concepts used; and, by analyzing the solutions, it is possible to identify the associations of those concepts within given problem situations. The implication for instructional theory is that the sequence of information for instruction should be based in part on internal situational associations as well as external structures. The assumption is that because external structures are independent of employment needs, an analysis of possible internal associations would improve the initial organization of the new information, resulting in better employment (Tennyson \& Elmore, 1997).

Situation and context analysis. In addition to the analysis of problems and solutions, is the issue of problem situation and/or context. For example, expert systems reside within the constraints of a specific context; that is, they can solve problems only associated with that given context; similarly, research in cognitive psychology shows that individuals can solve complex problems only if they possess the necessary contextual knowledge. For example, the objective in learning to play chess is the learning of problem solving strategies within the context of both the given game and the current move, not just how the various chess pieces move (i.e., procedural knowledge). Thus, the key to both effective acquisition and employment of knowledge is the organization of the knowledge according to contextual applications. That is, contextual knowledge includes not only content/task information, but also the cultural and situational aspects directly associated with that 
information (Brown, Collins, \& Duguid, 1989). Culture implies the selection criteria, values, feelings and appropriateness associated with the information of given contextual situations.

\section{Transition to Cognitive Instructional Theory}

Gagné and Briggs (1979) early on incorporated cognitive theory into their instructional theory for conceptualizing instructional design. They defined a set of requirements for instructional systems design, including the following:

- The system must be designed for the individual,

- It should include immediate and long-range phases,

- It should substantially affect individual development, and

- It must be based on knowledge of how people learn.

Their instructional theory was based on a set of capabilities, or learning outcomes, that students would acquire through instruction. These outcomes were classified into five categories: verbal information, intellectual skills, cognitive strategies, motor skills, and attitude. Instead of emphasizing generalized factors such as practice and reinforcement in the learning process, their theory required that the conditions of external events and internal processes must be specified separately for each learning outcome. Also important to their instructional design theory was the interaction of instruction with the student's previously acquired learning.

The Component Display Theory developed by M. David Merrill was a prescriptive instructional design theory rooted in Gagné's theories and directed toward improving instructional quality. Merrill and his collaborators worked to develop a taxonomy of instructional presentation types for conveying information and asking questions. Separating performance level from the content type extends the system of outcome classification (Merrill, 1997).

Another concept developed in the field of cognitive psychology that was relevant to instructional theory was learner production of knowledge. Investigations in cognitive strategies that guide internal learning and thinking processes resulted in specific strategies for such processes as problem solving, organizing information, reducing anxiety, developing self-monitoring skills, and enhancing positive attitudes. Researchers also investigated meta-cognition (a process of being aware of specific cognition skills) and the executive strategies experienced learners use to develop awareness and control of their own acquisition and employment of knowledge. Researchers paid renewed attention to the role of automaticity and the necessity of practicing subskills as a prerequisite foundation for more advanced learning (Winn, 1993).

\section{Integrated Instructional Design Theories}

By the 1990s, the trend in instructional design moved towards a synthesis of elements of the various instructional theories and advancements from cognitive science and educational technology. The notion of developing a single, most effective approach to all instructional 
situations was replaced by attempts to find the best approaches to achieve specific, well-defined performance outcomes in terms of knowledge and cognitive processes. The emphasis was on instructional variables and conditions based on individual learner progress and need. That is, by assessing the learner's progress, the learning need could be established from which appropriate instructional strategies, sequences, and media could be determined. The role of the instructor continued to change to reflect more flexibility in the learning environment. The role of technology changed as well, as instructional design researchers worked with computer software specialists to develop interactive instructional systems.

\section{Interactive Media and Learning}

Interaction of learners with media and learning environments became important in the late 1990s and continues to be an area of increasing focus during the first decade of the $21^{\text {st }}$ century. For example, the constructivist view of learning positions is that an active, self-regulated, goaldirected, and reflective learner constructs personal knowledge through discovery and exploration in a responsive learning environment. Interactive technologies that can adaptively and intelligently respond to at-the-moment learning needs and progress can activate that environment. Online interactivity is a vital area of research given the growth of the Internet. E-learning will expand as a delivery system and will be a major concern for educational technology researchers.

\section{Selecting Instructional Strategies}

While many instructional design experts continued to revise their theories in an attempt to arrive at a theory of instruction that could be applied to all learning situations, a number of theorists changed directions in the early 2000s. These researchers sought to analyze the theories already in existence to determine their relative strengths and weaknesses for dealing with specific instructional situations. Rather than trying to synthesize elements of the existing theories into a new hybrid theory, these researchers tried to assemble the strongest theories into large-scale, diverse systems that encompass many possible strategies. Strategies were combined in new ways to determine which combinations and sequences were most effective for well-defined instructional settings. Instructional designers could then select the specific segments of the larger, integrated instructional theories that were directly applicable to the learning outcomes they desired, introducing more flexibility into instructional design.

\section{Domain-Specific Competency: Structured vs. Self-regulation}

Researchers continue to investigate the processes and structures of competent performance in specific domains and to develop instructional programs to produce such competence. Two oftendichotomous stances toward instruction are reflected in such programs: structured approach and self-regulated approach.

Structured approach. One stance is that of a mastery approach, which emphasizes learning proceduralized knowledge through extensive practice with problem solving. In this paradigm, the 
teacher controls the direction of learning, with learners following a specific path of carefully structured sub-goals leading toward the efficient performance of a well-defined cognitive skill. Practice with successful performance is thought to lead to subsequent metacognitive abilities.

Self-regulated approach. A second stance toward instruction emphasizes self-regulated control of instructional strategies by the learner in accomplishing a complete, non-decomposed task. The teacher provides modeling of the metacognitive strategies necessary for beginning the task, and, when problems are encountered, assistance is provided by the teacher or group. One learning procedure reflecting this stance, Reciprocal Teaching, structures collaborative group works in sharing a complex problem-solving task. This approach is based on learning theories about the social genesis of learning in which the learner is characterized as being motivated to seek explanations through exploration.

Both the structured approach and the self-regulated approach share several underlying premises. One is that learning should be contextual and a process of active application of knowledge toward specific problem solving goals. Second is the general agreement regarding the importance of modeling problem-solving strategies as well as the role of conflict or failure in providing an impetus toward new learning. In contrast to the behaviorist view of the learner as shaped by the environment, instructional design researchers in 2000 are investigating ways that the learner can actively shape the environment to facilitate learning.

\section{Transition from Instructional Theory to Instructional Design Model}

Two examples of instructional theories are presented to illustrate the transition from learning theory to instructional design models. The two theories are the elaboration theory and the linking theory. These two instructional theories offer direct transitions between learning theory, instructional theory, and instructional design process and methodology. They are in fact cumulative theories that can be applied directly in the ID process.

\section{Elaboration Theory}

Elaboration theory is a theory of instructional design aimed at telling people how to teach rather than focusing on why and how people learn. It is concerned with the structure and organization of instructional material (stimuli) rather than the material itself. Elaboration theory is based on cognitive psychology and seeks to be consistent with cognitive theories of learning.

Two primary components of elaboration theory are: (a) that instruction should proceed from the general to the specific, referred to as sequencing; and, (b) that each part should be related to the general context and to the other parts, referred to as synthesizing. The method for implementing the theory is to start with a general overview of the material then divide it into parts and elaborate on each part. Each part is then further subdivided into smaller parts, which are elaborated, and those parts divided again, until the desired level of detail has been reached. 
In the sequencing procedure, the concept of an epitome is used. An epitome is much like an advance organizer; that is, an epitome is a general and brief summary of the material to be learned, intended to provide a general context for the new information. The synthesizing procedure is intended to facilitate the integration of new information with existing knowledge and to form meaningful relationships in cognitive structure.

\section{Linking Theory}

The second example of an instructional theory that illustrates the transition to instructional design models is the linking theory first proposed by Tennyson and Rasch (1988). This theory directly links learning theory to educational goals, learning objectives, and instructional prescriptions. Additionally, it goes beyond any other instructional theory by attaching specific allocations of academic learning time to desired educational goals and objectives (Table 1).

Table 1. Linking Theory

Educational Goals

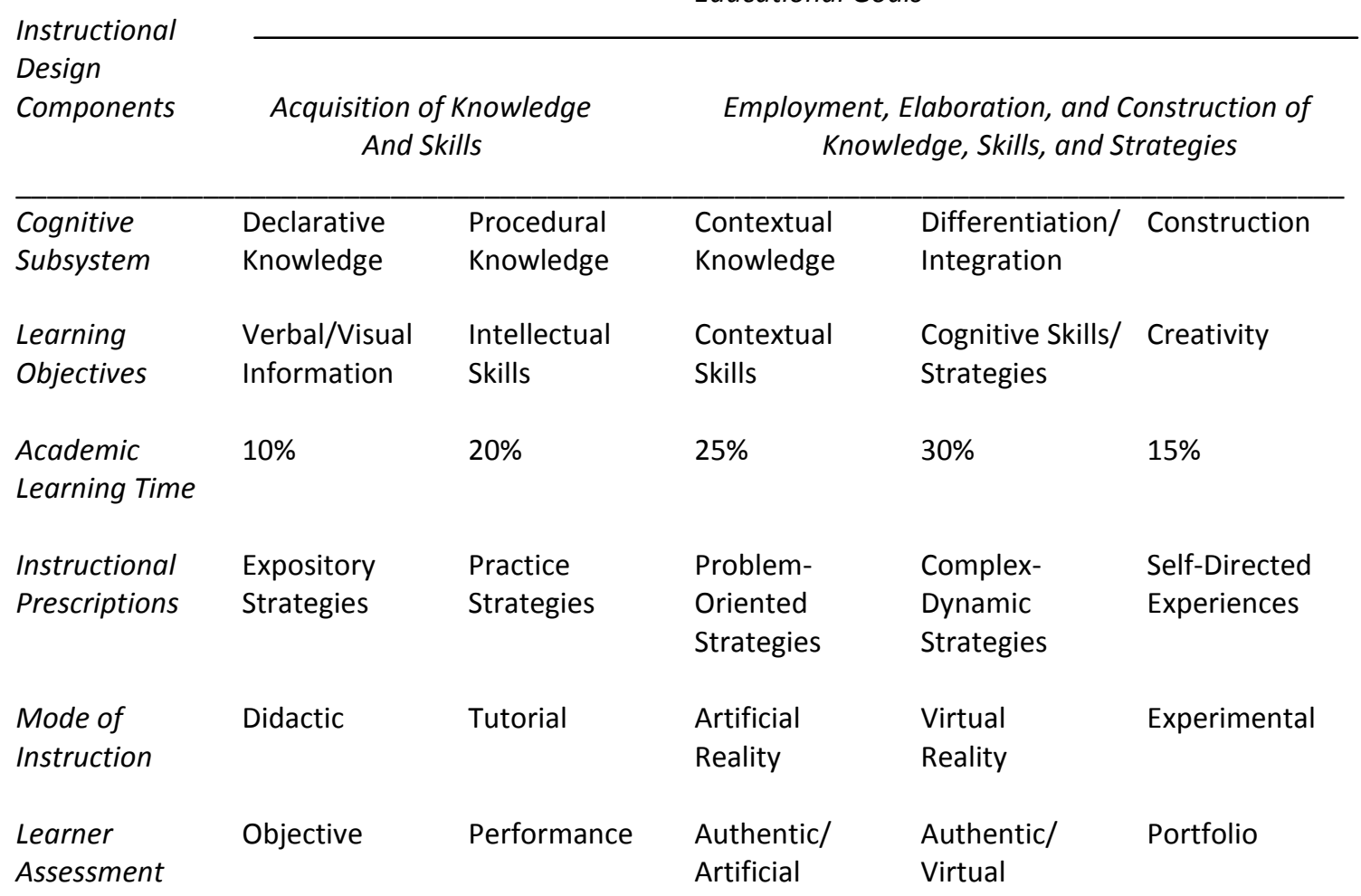

Tennyson and Rasch prescribe an instructional design theory that includes behavioral, cognitive, and contextual learning theories with appropriate instructional prescriptions. By allocating academic learning time across a range of learning objectives they blend the structured and selfregulated philosophical approaches to learning. In the acquisition of knowledge both structured and self-regulated strategies are employed. While the goal is improving employment of 
knowledge, they specify both group and individual situations to help learners elaborate and extend their individual knowledge bases and cognitive processes.

In this article I extend the Tennyson and Rasch linking model by adding two instructional design components. These two additions are mode of instruction and learner assessment. The revised model is presented in Table 1. The six instructional design components of the linking theory form a matrix, crossing with the educational goals of knowledge and skill acquisition with employment, elaboration, and construction of knowledge, skills, and strategies.

The learning philosophy of the linking theory is embedded in these two educational goals, which emphasize the roles of the teacher, peer, and self in the learning process. Thus, it makes use of four basic concepts of a philosophy of learning: Nature, nurture, self, and society. Nurture is highlighted by the design of the learning environment by the instructional designer. Planning is essential to the application of the linking theory. On the other hand, the self is primarily responsible for a large part of the learning process and management. This also includes the concept of nature as having a major effect on self-regulation aspects of learning. Society is integral mode of instruction in those objections reflecting higher order cognitive activities in problem solving, decision making, and trouble shooting. Finally, learner assessment methods are directly linked to the other five instructional design components. Too often, learner assessment is reduced to only one or two forms, thereby, attempting to generalize to other educational goals. The assumption in the revised linking theory is that assessment methods should reflect the type of learning that is occurring.

The linking theory emphasizes that learning involves three types of knowledge (declarative, procedural and contextual), each requiring a different instructional prescription. Selection of a given instructional prescription is based on an analysis of the content and learner need. The information analysis focuses on the context of the learning situation rather than a behavioral or features analysis. The instructional prescriptions are as follows:

- Expository (context statement, label/definition, best example, matched/divergent examples, and worked examples).

- Practice (problem examples, feature elaboration, and feedback strategies).

- Problem-oriented (contextual modules-simulations, case studies, role playing-with cooperative learning).

- Complex-dynamic (situational units-complex simulations, case studies, role playing-with cooperative learning).

- Self-directed experiences (manipulative software, lab/field experiments, projects).

A key factor in implementing the educational goals of knowledge acquisition and employment in the Tennyson and Rasch instructional design theory is the allocation of academic learning time by defined learning objectives. For example, they suggest that if improvements in problem solving and creativity are to occur, there needs to be a significant change in how instructional time is allocated. They recommend that the conventional instructional time allocation for learning be altered so that, instead of $70 \%$ of instruction aimed at the declarative and procedural knowledge 
levels of learning, $70 \%$ be devoted to learning and thinking situations that involve acquisition of contextual knowledge and development of cognitive abilities of differentiation, integration, and construction.

Tennyson and Rasch recommend allocation of instructional prescriptions and academic learning time (ALT) according to the following learning objectives:

- Verbal/Visual Information. The learner is aware of meaning and understanding of declarative knowledge (e.g., facts, propositions, rules, principles, and concepts).

- Intellectual Skills. The student is able to employ procedural knowledge with newly encountered situations and problems).

- Contextual Skills. The learner is able to employ declarative and procedural knowledge in complex situations and problems.

- Cognitive Skills/Strategies. The learner is able to employ the cognitive complexity strategies of differentiation and integration in the service of dynamic situations and problems.

- Creativity. The learner is able to construct necessary knowledge in both predefined and selfdefined situations and problems.

For the educational goal of knowledge acquisition (see Table 1), ALT is allocated among the three cognitive subsystems making up a knowledge base as follows: declarative knowledge $10 \%$; procedure knowledge 20\%; and contextual knowledge 25\%. They recommend that contextual knowledge ALT be about equal to the other two knowledge forms because of the necessity to both organize a knowledge base and develop cognitive skills necessary to access appropriate knowledge (i.e., the why as well as the when and where). They maintain that the value of a knowledge base is primarily in the functionality of its organization and accessibility. Without a sufficient base of contextual knowledge, the opportunity for employment, future elaboration, and extensions of the knowledge base is limited.

For the knowledge and skill acquisition goal, the focus of ALT allocation is on contextual knowledge. This is in contrast to the usual practice in education of heavy emphasis on amount of knowledge acquired. As such, they emphasize a context learning theory base that assumes that declarative and procedural knowledge acquisition is an interactive process that is improved when employing the knowledge base in the service of higher-order thinking situations (i.e., problem solving and creativity). In their instructional design theory, time allocated for declarative and procedural knowledge focuses on establishing an initial base of necessary knowledge that can be used within a context of a problem situation. That is, learning time should include the opportunity for the learner to gain experience in employing, elaborating, and constructing knowledge, skills, and strategies.

The learning times presented in Table 1 do not imply a step-by-step sequence of knowledge acquisition going from declarative to contextual. Rather, they represent curricular times in an iterative learning environment where learners are continuously acquiring each form of knowledge. For example, students may engage in contextual knowledge acquisition prior to declarative 
knowledge acquisition if they currently have sufficient background knowledge (i.e., a problemoriented strategy of instruction as contrasted to a structured method).

Teaching methods form the core of the mode of instruction instructional design component. In this application, the linking theory favors methods of instruction that are directly related to the desired learning objectives. Modes of instruction include a range of learning theories from behavioral to constructivism as follows:

- Didactic (Structured form of delivery, e.g., lecture, books, print, video, etc.)

- Tutorial (Structured form of delivery with high interactivity between learner and medium of instruction.)

- Artificial Reality (Self-regulated forms of contextual situations.)

- Virtual Reality (Self-regulation of the decision rules--e.g., complex/dynamic simulations)

- Experimental (Self-regulation of the learning tools and management of environment.)

Learner assessment is area of educational and psychological foundations that has seen much growth in the two last decades of the $20^{\text {th }}$ century. Research work in testing and measurement is tied to the range of developments in learning theory. Classical measurement theory is based in the behavioral tradition of observable behaviors and rigorous quantitative statistical methods. Cognitive psychology has leaded the search for more process related methods of assessment through item response theory and adaptive testing methods. More recently, the need to evaluate learner higher order cognitive activities that do not lend themselves to right or wrong answers, and that exhibit growth rather than just end of instruction performances, has seen developments in portfolio types of learning evidence. The linking theory includes the following types of learner assessments:

- Objective (Standardized testing format with correct and incorrect answers.)

- Performance (Standardized format with range of outcomes from high to low.)

- Authentic/Artificial (Standardized format in a contextual environment with a range of outcomes from known criteria.)

- $\quad$ Authentic/Virtual (Open-ended format with criteria determined by the learner from normed validity.)

- Portfolio (A collection of works, exhibitions, and experiences constructed by the learner. Evaluation from learner defined validity.)

\section{Recommendations}

I conclude by offering several recommendations for preparation of a personal (i.e., individual instructional designer or organization) instructional theory that would compliment a written educational learning philosophy and theory statements. These recommendations include the following: 
- Instructional theory should be usable. It should be stated with enough clarity to allow successful implementation;

- Instructional theory should be valid. It should have evidence of empirical testing and practical evaluation;

- Instructional theory should be theoretical. It needs to explain theoretically how a particular instructional procedure works; and,

- Instructional theory should be linked to learning theory. It must use the wealth of research in learning and cognition.

A fundamental improvement offered by learning theory is the explicit placement of educational foundations into the methodology of instructional systems design. There are two reasons for this overt action. First, ISD was founded during a period in which American behaviorist philosophy and learning theory was the dominant foundational force in education. Most educational practices and methods were by default thought to be founded in behaviorism. Practices and methods of classroom teaching and assessment assumed to have an underlying behavioral nature whether they did or not. What developed in the absence of a strong commitment to defining a philosophy for educational practice was the growing acceptance of fads as the solutions to learning problems in American schools. Tracing a new method or practice to a well-defined philosophy or even learning theory was dropped as part of the educational process. Much of the blame for ills in American education continues to be placed ironically on the last (and perhaps only) large-scale educational philosophy defined in this country. That philosophy was developed in the $1930 \mathrm{~s}$ at the prestigious schools of education at Teachers College, Columbia University and University of Chicago. What was known as the progressive movement profoundly changed both American curricula and classroom instructional methods. The paradox is that most schools today do not resemble in any way the progressive philosophy. However, because the scientific method of linking learning theory with instructional design, that is in turn confirmed by research before employment, continues to be ignored in educational practice.

Instructional design models continued the usual educational practice of adopting methods of doing with minimal concern for theoretical learning foundations. It is not surprising then that early instructional design theory assumed the prevalent learning theory at their time of conception. Later, instructional designers in piece meal fashion adopted the new ideas associated with cognitive psychology. Likewise, the fads currently circulating with constructivism seem to suggest that a systemic change in the process of education is needed. The fad nature of constructivism is to view instructional design as only capable of performing behavioral actions. However, the problem with instructional development continues to be the lack of a means of defining a philosophy and learning theory by which the instructional design methodology can be driven.

\section{Conclusion}

Although building on earlier theories of learning, researchers working toward interactive technologies perceived limitations in earlier methods. By developing instructional theories that 
emphasize synthesis and integration of sets of knowledge and skills, researchers hope to address such limitations as:

- An emphasis on components instead of integrated wholes,

- A closed instructional system that makes incorporation of new knowledge difficult and which results in essentially passive instruction, and

- The labor-intensive practice in design and development of instruction.

\section{Future Trends in Instructional Theory}

Human relations and resources will likely be a center of much instructional design progress in the coming years. Learner variables, for example, have already begun to play an important role in instructional theory, and the area of motivation promises to be of particular significance in the near future. The role of the instructor has again emerged as a topic of interest. Instructional design researchers are concluding that a major contributing factor inhibiting the acceptance of instructional design principles in the K-12 school system is the resistance of teachers. It will be necessary for instructional design advocates to address the issues of teacher involvement if they hope to implement their systems/models in the K-12 educational domain. I look for future instructional systems design models to take into account the unique situation of teachers. For the most part, ISD models assume development of new materials whereas teachers rarely if ever develop new materials. Rather teachers, with good foundation knowledge, will adapt or adopt existing instructional materials. The employment of instructional theory for teachers would focus on how to evaluate the foundations of existing materials within a maintenance program.

\section{Learner-Centered}

I also expect that instructional designers will concentrate increasingly on developing instructional theories that are learner-centered rather than technology-centered. The shift of emphasis may, in the long run, improve the effectiveness of computer delivery systems (e.g., Internet applications in education) by allowing software to catch up with hardware and thereby improve application coordination. This trend does not, however, discount the importance of technological advances to the future of instructional design. Some areas of particular interest include increased: development of automated ISD expert systems with extensive authoring capabilities to aid inexperienced developers; design of simulations which create low-risk environments for learners trying to acquire complex skills (Tennyson \& Breuer, 1997); and emphasis on the level of interactivity between computers and learners (Seel \& Winn, 1997).

\section{Quantitative and Qualitative Research}

It is likely that disciplined, quantitative and qualitative research methods will both play greatly increased roles in the future of instructional theory. Quantitative research, long linked with the behaviorist tradition, has been largely displaced by the more intuitive approach of the cognitive movement. Instructional designers are beginning to recognize that many aspects of the ISD 
methodology could profit by more rigorous research methods, rather they be quantitative or qualitative.

\section{Meta-Theories}

In general, I predict that the instructional design field will finally abandon the pursuit of a single, all-encompassing instructional theory and concentrate on establishing an interactive network of meta-theories. Instructional designers, I believe, will increasingly choose to apply a particular learning and/or instructional theory only to those narrow learner outcomes toward which it works most effectively. The acquisition of a complex mental skill might, for example, include learning various subskills on the basis of several different learning theories. The result would be enhanced flexibility and increased efficiency. Instructional designers could then take the process a step further and alter each of the original models used on the basis of formative evaluation at the subskill level. These refinements hold great promise for fluid, complex instructional designs, but can only emerge from a spirit of balance and increased cooperation among instructional designers in both academic and applied environments.

\section{References}

Ausubel, D. P. (1969). A cognitive theory of school learning. Psychology in the Schools, 6, 331-335.

Breuer, K., \& Kummer, R. (1990). Cognitive effects from process learning with computer-based simulations. Computers in Human Behavior, 6, 69-81.

Brown, J. S., Collins, A., \& Duguid, P. (1989). Situated cognition and the culture of learning. Educational Researcher, 18, 32-42.

Bruner, J. S. (1964). Study of thinking. New York: Wiley.

Carroll, J. B. (1993). Human cognitive abilities. New York: Cambridge University Press.

Dewey, J. (1910). How we think. Boston: D.C. Heath.

Finn, J. D. (1957). Automation and education: General aspects. AV Communications Review, 5, 343360.

Gagné, R. M. (1962). Military training and principles of learning. American Psychologist, 17, 83-91.

Gagné, R. M., \& Briggs, L. J. (1979). Principles of instructional design ( $2^{\text {nd }}$ ed.). New York: Holt, Rinehart, \& Winston.

Mager, R. (1962). Instructional behavioral objectives. San Francisco: Fearon Press.

Merrill, M. D. (1997). Instructional transaction theory: An instructional design model based on knowledge objects. In R. D. Tennyson, F. Schott, N. Seel, \& S. Dijkstra (Eds.), Instructional design: International Perspectives, Vol. I: Theory and research (pp. 215-241). Mahwah, NJ: Erlbaum.

Scandura, J. M. (1970). The role of rules in behavior: Toward an operational definition of what (rule) is learned. Psychological Review, 77, 516-533. 
Schott, F., \& Driscoll, M. P. (1997). On the architechtonics of instructional theory. In R. D. Tennyson, F. Schott, N. Seel, \& S. Dijkstra (Eds.), Instructional design: International Perspectives, Vol. I: Theory and research (pp.135-173). Mahwah, NJ: Erlbaum.

Seel, N., \& Winn, W. D. (1997). Research on media and learning: Distributed cognition and semiotics. In R. D. Tennyson, F. Schott, N. Seel, \& S. Dijkstra (Eds.), Instructional design: International Perspectives, Vol. I: Theory and research (pp.293-326). Mahwah, NJ: Erlbaum.

Skinner, B. F. (1954). The science of learning and the art of teaching. Harvard Educational Review, 24, 86-97.

Snow, R. E. (1997). Individual differences. In R. D. Tennyson, F. Schott, N. Seel, \& S. Dijkstra (Eds.), Instructional design: International Perspectives, Vol. I: Theory and research (pp. 215-241). Mahwah, NJ: Erlbaum.

Tennyson, R. D., \&. Elmore, R. L. (1997). Learning theory foundations for instructional design. In R. D. Tennyson, F. Schott, N. Seel, \& S. Dijkstra (Eds.), Instructional design: International Perspectives, Vol. I: Theory and research (pp. 55-78). Mahwah, NJ: Erlbaum.

Tennyson, R. D., \& Rasch, M. (1988). Linking cognitive learning theory to instructional prescriptions. Instructional Science, 17, 369-385.

Thorndike, E. (1913). The psychology of learning: Educational psychology (Vol. 2). New York: Teachers College Press.

Winn, W. (1993). A constructivist critique of the assumptions of instructional design. In T. M. Duffy, J. Lowyck, \& D. H. Jonassen (Eds.), Designing environments for constructive learning (pp. 213-234). Berlin: Springer.

Correspondence: Robert D. Tennyson, Learning and Cognition, Department of Educational Psychology, University of Minnesota, 250 Education Sciences Bldg, Minneapolis, MN 55455, USA. 